\title{
Lasers in the Treatment of Vascular Anomalies
}

\author{
Tara L. Rosenberg • Gresham T. Richter
}

Published online: 21 September 2014

(C) Springer Science+Business Media New York 2014

\begin{abstract}
Lasers have become an integral part in the management of hemangiomas and vascular malformations of many types. Patient outcomes have improved with new discoveries in laser technology and technique. This comprehensive review provides the parameters by which lasers are employed for common vascular anomalies of the head and neck. Research is still needed to identify ideal laser wavelength and treatment intervals for the variety of vascular lesions encountered.
\end{abstract}

Keywords Vascular anomalies - Lasers - Treatment . Vascular malformations - Port-wine stain - Hemangioma

\section{Introduction}

The International Society for the Study of Vascular Anomalies (ISSVA) was founded in 1992. From this organization was adopted a widely accepted classification system for vascular anomalies that originated from the initial work of Mulliken and Glowacki in 1982 [1, 2]. Vascular anomalies were divided into two broad categories, namely vascular tumors and vascular malformations. These categories differentiated vascular anomalies based upon their clinical, histologic, radiologic, and biologic behavior [3]. The most common vascular tumor is the

\footnotetext{
T. L. Rosenberg $(\bowtie) \cdot$ G. T. Richter

Department of Otolaryngology/Head and Neck Surgery, Vascular Anomalies Center, University of Arkansas for Medical Sciences, Arkansas Children's Hospital, 1 Children's Way, Slot 668, Little Rock, AR 72202, USA

e-mail: tlrosenberg@uams.edu

G. T. Richter

e-mail: gtrichter@uams.edu
}

infantile hemangioma. Vascular malformations are characterized by their vessel type to include capillary, venous, lymphatic, arteriovenous and combined lesions. The name used to describe a vascular malformation therefore is based on its major vessel constituents.

Laser treatment of vascular anomalies has undergone significant advances since it began in the 1960s. Port-wine stains (PWS) and hemangiomas were treated with continuous wave argon and carbon dioxide $\left(\mathrm{CO}_{2}\right)$ lasers. Unfortunately, undesirable scarring and skin surface changes from thermal damage limited the use of these lasers for vascular lesions. Anderson and Parrish in the 1980s however, revolutionized laser treatment of skin and vascular lesions [4].

Selective photothermolysis is the principle described by Anderson and Parrish [5] that identified chromophores, such as oxyhemoglobin or melanin, as cellular components that can selectively absorb laser energy at a particular wavelength. The energy absorbed is converted to heat, resulting in a fatal injury to the cell. Thus, lasers of various wavelengths can be chosen to specifically target and ablate different types of tissues or cells within and just deep to the skin.

The principle of selective photothermolysis also involves the concept of thermal relaxation time (TRT). TRT is the amount of time required for a tissue, exposed to laser light, to lose $50 \%$ of its incident heat. Injury to adjacent tissue occurs when laser light is administered for time periods greater than the TRT of the target. When laser light is delivered to the target tissue at a long enough duration (known as the pulse duration), then the target tissue is heated faster than it can cool. This causes a focused increase in thermal energy in the target and a fatal injury to the cell. If the pulse duration is continuously increased, the thermal injury extends to collateral or non-target cells as well [4]. 
Since many hemangiomas and vascular malformations invade local tissue to cause functional and aesthetic problems, seletive laser treatment, with protection of normal surrounding tissue, became an attractive option for patients afflicted with these lesions. Vascular lesions that respond best to laser treatment are those that are slow-flow, superficial, and/or of small vessel caliber, as they are better able to concerntrate the thermal energy. Examples of such lesions include superficial hemangiomas, capillary malformations (PWS), and mucosal or skin venous and lymphatic malformations (VMs). Clinical work is being performed to identify laser options for patients with fast flow lesions like arteriovenous malformations (AVMs). This review provides the lasers and their parameters by which they can treat various hemangiomas and vascular malformations.

\section{Fundamental Principles of Lasers}

The term laser is an acronym: light amplification by the stimulated emission of radiation. The emission of radiation is in the form of light energy is measured in watts (W). Power density (i.e., fluence) is the amount of light energy delivered to a specific area and is measured in watts per square centimeter $\left(\mathrm{W} / \mathrm{cm}^{2}\right)$. Joules (watt per second) is the measurement used to define the total dose of light exposed to a specific tissue. One joule is equal to a tissue exposed to one watt for one second. Pulsed laser output is measured in joules, while continuous wave laser output is measured in power (usually in watts) [4].

Light energy interacts with tissue in various ways. The target tissue absorbs most of the light, the primary intent of laser therapy. A portion of the light is scattered into surrounding tissue. Some of the light is reflected off the tissue, and parts of the light can transmit through the tissue. Each laser emits light in a specific wavelength and is collimated (i.e., all in one direction). Each laser wavelength is absorbed uniquely by various tissues. Deeper penetration is achieved by lasers of specific wavelengths [4].

As mentioned, lasers of different wavelength are selectively absorbed by different chromphores. For the majority of vascular lesions, the target chromophore for laser treatment is hemoglobin (either oxygenated or deoxygenated form). Lasers with long wavelengths treat more superficial lesions due to their limited depth of penetration. The opposite is true for lasers with shorter wavelengths. Pulse duration can also be chosen to selectively ablate vessels of different sizes. Smaller vessel lesions require less time (i.e., shorter pulse duration) to cause destruction of the vessel. Small vessel diameters are usually around $100 \mu \mathrm{m}$ or less (e.g., early PWS, proliferating hemangiomas). These lesions may be treated by lasers such as the flashlamp-pumped dye laser (or pulsed dye laser) with pulse duration of 500-1500 $\mu$ s.
Medium sized vessels typically have diameters of 100-400 $\mu \mathrm{m}$ (e.g., intermediate and advanced PWS, involuting hemangiomas), and require a pulse duration between 10 and $100 \mathrm{~ms}$ for treatment. Potassium-titanyl-phosphate (KTP) laser may be successfully used for these vessels. Large vessels typically have diameters greater than $400 \mu \mathrm{m}$ in width (e.g., advanced PWS, VMs), and require even longer pulse duration (i.e., around 0.1-1 s). Neodymium:yttriumaluminum-garnet (Nd:YAG) lasers are able to deliver this length of pulse and are ideal for these anomalous vessels of this size [4]. Laser wavelengths and setting for the most commonly treated vascular anomalies are listed in Table 1.

Laser safety is of utmost importance for the patient and staff. The eye is the most vulnerable organ to laser light damage and is best prevented by various forms of eye protection. Manufacturer guidelines and safety goggles have been established for each individual laser. Fire precautions and laser equipment guidelines should also be followed to prevent thermal or electric risk to the patient and operating surgeon or technician [4].

\section{Hemangiomas}

Hemangiomas are the most common vascular tumor [3]. They are divided into infantile hemangiomas (IH) and congenital hemangiomas $(\mathrm{CH})$. IHs occur in approximately $5 \%$ of children and undergo an unique rapid growth phase (proliferating phase) over a few weeks to months of life. They then enter a brief quiescent period and slowly regress over several years (involution). The final stage of involution is usually reached by 5-6 years of age. The involuted phase can result in normal-appearing skin, atrophic skin, fibro-fatty residuum, or a combination of these findings. The endothelium of IH immunostains positive for glucose transporter-1 protein (GLUT-1) [3]. Hemangiomas are classified as either focal or segmental. Segmental lesions are larger, diffuse, plaque-like, and aggressive [7•].

Congenital hemangiomas are present in their full form at birth. They do not undergo post-natal growth like IHs. CHs occur in two forms: non involuting congenital hemangiomas (NICH) and rapidly involuting congenital hemangiomas (RICH). RICHs regress very rapidly after birth, usually over 6-14 months. NICHs do not undergo any regression and therefore persist indefinitely. NICH and RICH endothelium does not stain with GLUT-1 antibody [3].

Based upon appearance, IHs are classified into superficial, compound (involving the skin and subcutaneous structures), and deep. Hemangioma candidates for laser treatment include precursor lesions, early superficial disease (especially in more cosmetically sensitive areas), superficial or compound hemangiomas complicated by skin ulceration/ bleeding [8•], superficial hemangiomas with very rapid 
Table 1 Laser wavelengths, settings, and additional information for the most commonly treated vascular anomalies

\begin{tabular}{|c|c|c|c|}
\hline Laser & $\begin{array}{l}\text { Main indications in vascular } \\
\text { anomalies }\end{array}$ & Typical settings & Additional information \\
\hline FPDL 595 nm & $\begin{array}{l}\text { Hemangiomas, port-wine stains, and } \\
\text { others }\end{array}$ & $\begin{array}{l}2 \text { Main options: } \\
\text { Joules: } 8-15 \mathrm{~J} \\
\text { Duration: } 0.45 \text { to } 1.5 \mathrm{~ms} \\
\text { Spot size: } 7 \mathrm{~mm} \\
\text { Joules: } 8-10 \mathrm{~J} \\
\text { Duration: } 1.5 \mathrm{~ms} \\
\text { Spot size: } 10 \mathrm{~mm}\end{array}$ & $\begin{array}{l}\text { Place coolant on maximum level. Joules } \\
\text { vary based on initial skin response. } \\
7 \mathrm{~mm} \text { spot is most frequently used with } \\
\text { average treatment range between } 8-15 \mathrm{~J} \text {. } \\
\text { With } 10 \mathrm{~mm} \text { spot size, maximum Joule } \\
\text { is } 10 \mathrm{~J} \text { because of the limits of the } \\
\text { machine. The smaller the spot size, the } \\
\text { higher the Joule maximum level. }\end{array}$ \\
\hline $\begin{array}{l}\text { Alexandrite } \\
755 \mathrm{~nm}\end{array}$ & $\begin{array}{l}\text { Hemangiomas, Port-Wine Stains, and } \\
\text { others (often used on lesions that are } \\
\text { resistant to FPDL treatment and } \\
\text { lesions with more purple coloration) }\end{array}$ & $\begin{array}{l}\text { Joules: } 60-100 \mathrm{~J} \\
\text { Duration: } 3 \mathrm{~ms} \\
\text { Spot size: } 8 \mathrm{~mm} \\
\text { Hertz: } 1 \mathrm{~Hz} \\
\text { Coolant settings: Pre 90/delay } \\
\text { 80/ post Off }\end{array}$ & $\begin{array}{l}\text { Joule level varies with skin response. } \\
\text { Great care should be taken when using } \\
\text { on patients with high fitzpatrick levels } \\
\text { (darker skin). It will be absorbed by } \\
\text { melanin and can result in } \\
\text { hypopigmentation. }\end{array}$ \\
\hline $\begin{array}{l}\text { Gentle YAG } \\
1,064 \mathrm{~nm}\end{array}$ & $\begin{array}{l}\text { Various vascular anomalies, usually } \\
\text { venous malformations }\end{array}$ & $\begin{array}{l}2 \text { Main options: } \\
\text { Joules: } 180-220 \mathrm{~J} \\
\text { Duration: } 20 \mathrm{~ms} \\
\text { Spot size: } 3 \mathrm{~mm} \\
\text { Joules: } 80-100 \mathrm{~J} \\
\text { Duration: } 20 \mathrm{~ms} \\
\text { Spot size: } 8 \mathrm{~mm} \\
\text { Constant settings: Hertz: } 1 \mathrm{~Hz} \\
\text { Coolant settings: pre } 40 / \text { delay } \\
\text { 30/post off }\end{array}$ & $\begin{array}{l}\text { Consider this laser on darkly pigmented } \\
\text { skin. } 8 \mathrm{~mm} \text { spot size maxes out at } 120 \mathrm{~J} \text {. } \\
\text { Referred to as "gentle" due to the } \\
\text { coolant spray. Same wavelength as } \\
\text { Nd:YAG laser. Joules vary with } \\
\text { response. Pentrates up to } 8 \mathrm{~mm} \text { to get } \\
\text { deep venous lesions. }\end{array}$ \\
\hline Nd:YAG 1,064 nm & $\begin{array}{l}\text { Venous malformations (airway, intra- } \\
\text { oral and interstitial treatments) }\end{array}$ & $\begin{array}{l}\text { Most settings are standard } \\
\text { Watts: } 15-30 \mathrm{~W} \\
\text { Duration: } 1-2 \mathrm{~ms}\end{array}$ & $\begin{array}{l}\text { Various hand pieces and fibers exist for } \\
\text { use to reach difficult locations. } \\
\text { Predominately used to manage mucosal } \\
\text { venous malformations of the } \\
\text { aerodigestive tract. SFE } 0.6 \text { fiber is used } \\
\text { to pass the ND:YAG laser interstitially. } \\
\text { This is performed through a 14-gauge } 1 \\
1 / 4 \text { needle (Fig. } 5 \text { ) }\end{array}$ \\
\hline
\end{tabular}

growth, and involuting/involuted hemangiomas with residual superficial skin changes and telangiectasias [9•].

The most commonly used laser in the treatment of $\mathrm{IH}$ is the pulsed dye laser (PDL). Other lasers such as the gentle YAG and fractionated $\mathrm{CO}_{2}$ laser have been employed. In most situations, the PDL is the first-choice when treatment is indicated. Gentle YAG lasers, which emit light at a higher wavelength, may be used to treat deep lesions with large deoxygenated hemoglobin containing vessels. The fractionated $\mathrm{CO}_{2}$ laser is used in skin resurfacing of atrophic skin changes caused by IHs [10]. Risks of any laser treatment to IHs include ulceration, scarring, hypopigmentation, hyperpigmentation, temporary purpura, blistering, swelling, and pain [11-13].

Superficial IH may be treated by PDL during the proliferation phase. They respond to PDL with a resultant decrease in the amount of total IH growth (Fig. 1) [8•]. Garden et al. determined that lesions greater than $3 \mathrm{~mm}$ thick do not respond as well to PDL [14]. The benefit of PDL for deep and compound hemangiomas is limited by the depth of penetration $(2-3 \mathrm{~mm})$ [15].

Involuted IHs can also benefit from PDL therapy. Residual and overlying telangiectasias, seen in many late involuted IHs, are small and superficial and make them good candidates for PDL vessel ablation. If there are significant scarring or skin textural irregularities following surgery or atrophic skin injury, the fractionated $\mathrm{CO}_{2}$ laser can resurface the skin to provide a smoother appearance [10]. The residual fibrofatty tissue of IHs does not respond to PDL laser treatment. In involuted lesions with significant volume, surgical excision will achieve the best cosmetic outcome.

Subglottic hemangiomas are rare but can be life threatening due to airway obstruction. They present with biphasic stridor during the proliferative phase at 6-12 weeks of age. Patients with cutaneous IH in the beard distribution are at increased risk $(>50 \%)$ of having 
Fig. 1 Pediatric patient with a superficial infantile hemangioma. a Appearance of lesion prior to treatment and b appearance after three treatments with pulsed dye laser
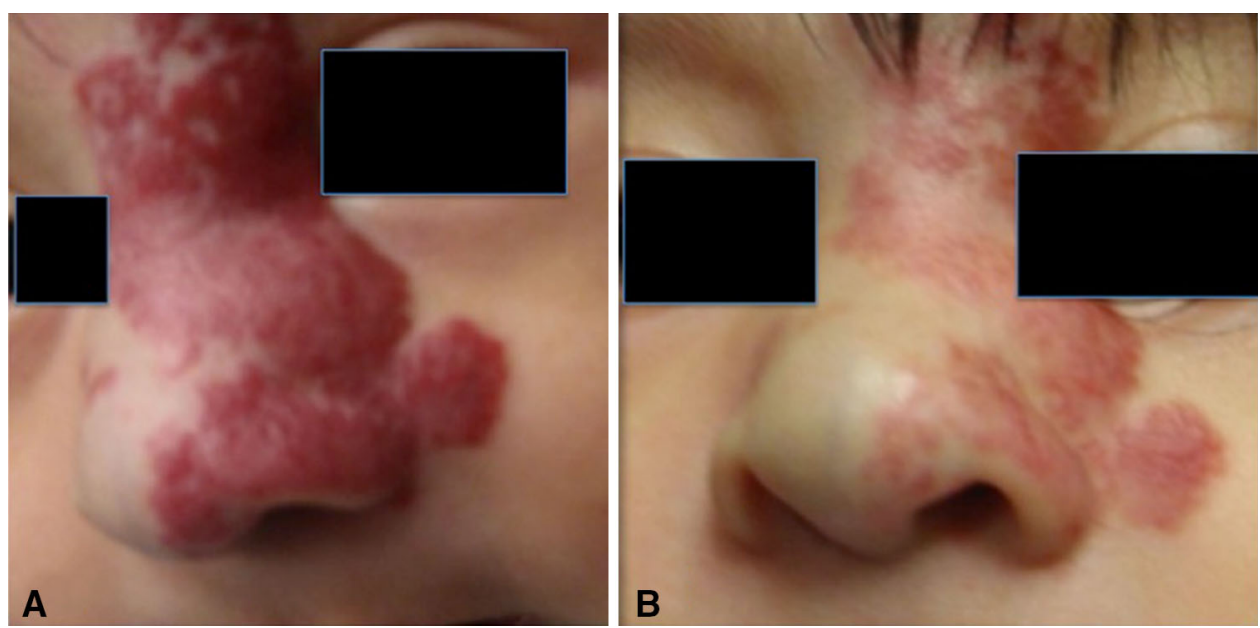

B

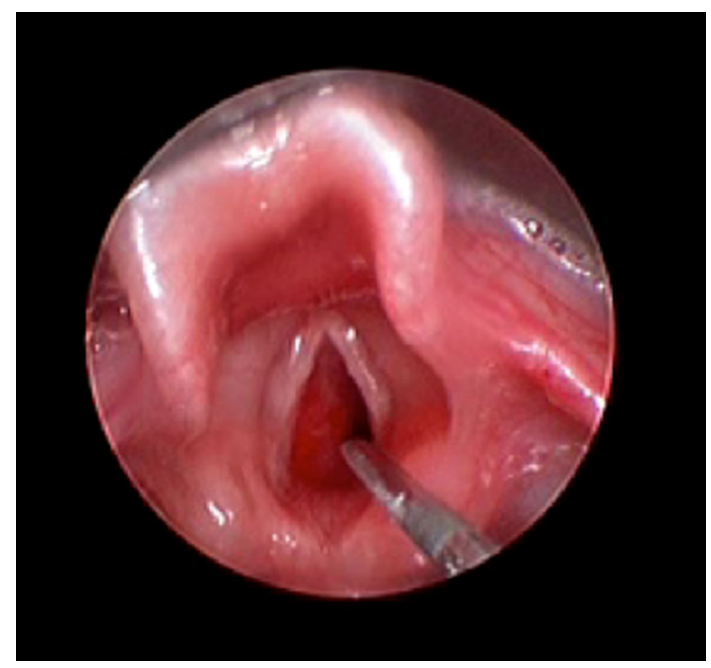

subglottic hemangiomas. In addition, one must be aware of the possibility of PHACES syndrome (posterior fossa malformation, hemangiomas, arterial anomalies, cardiac defects, eye abnormalities, and sternal defects) in these patients. There are multiple treatment methods for subglottic hemangiomas including oral propranolol, systemic steroids, open excision, intralesional steroid injection and laser ablation [16, 17]. Various lasers have been selected for the treatment of subglottic hemangiomas, but the $\mathrm{CO}_{2}$ laser is most commonly used. The $\mathrm{CO}_{2}$ laser has a success rate of around $89 \%$ in effectively reducing the size of the $\mathrm{IH}$ and improving symptoms. The risk of subglottic stenosis in the setting of repeated or aggressive treatments is real especially when injury to the underlying perichondrium occurs [16].

Large, multiple, or complicated IH are now being treated with propranolol as a first-line medical therapy. Excellent response rates have been reported and obviate the need for surgery in many cases $[18,19]$. Thus, propranolol is now supplanting $\mathrm{CO}_{2}$ laser as the tool to treat complicated IH or subglottic IH when initiated in combination with an intralesional steroid injection of kenalog/celestone (Fig. 2).

\section{Port-wine Stains}

Port-wine stains (PWS) are capillary malformations of the dermis, the majority (approximately $75 \%$ ) of which are located in the head and neck [20]. Capillary malformations are the most common congenital vascular malformation, with occurrence in approximately $0.1-0.3 \%$ of infants [21]. They appear as flat, macular lesions with a red to purple vascular stain of the skin. In time, the ectatic blood vessels forming these malformations progressively enlarge in diameter. If left untreated, the affected area of skin darkens and hypertrophies to cause thick and nodular
Fig. 2 Intraoperative view of endoscopic intralesional injection of kenalog/celestone into a subglottic hemangioma

lesions that lead to disfigurement and psychological disturbance $[22,23]$.

Port-wine stains can be complicated by glaucoma when they are present on the face near the eyes. They may also be associated with Sturge-Weber syndrome [22], which is a sporadic congenital neuro-oculo-cutaneous disorder. The classical definition of Sturge-Weber involves PWS in the skin distribution of the ophthalmic branch of the trigeminal nerve $\left(\mathrm{V}_{1}\right)$, involvement of the leptomeninges of the brain, and eye involvement. Sturge-Weber may include glaucoma, seizures, stroke, and intellectual disability [24]. Described incomplete forms also exist. PWS involving the entire $V_{1}$ distribution are more likely to be associated with the ocular and/or neurologic findings [25].

Like most vascular malformations, PWS integrate into the normal tissue of which they involve. Selective treatment of the small and anomalous vessels of PWS can be 


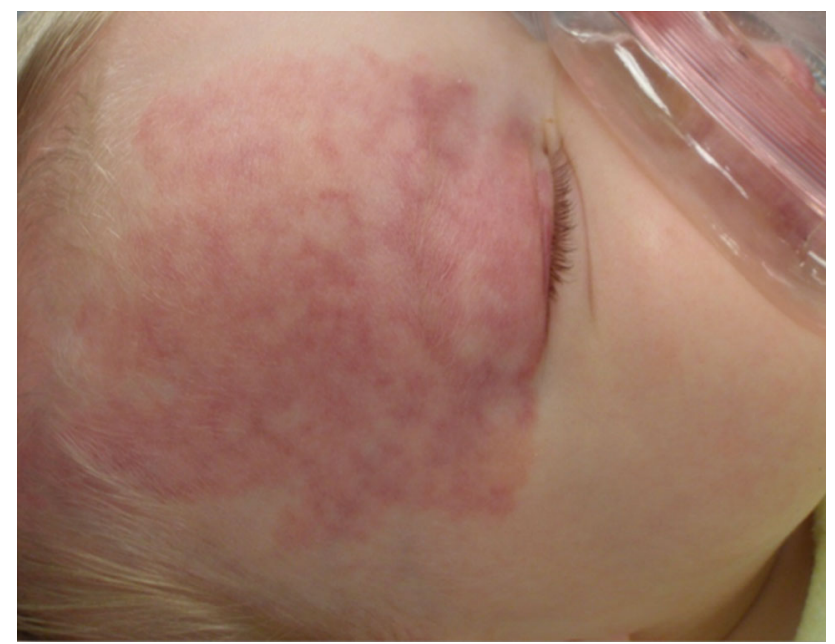

Fig. 3 Pediatric patient with a right facial capillary malformation (port-wine stain) several weeks after first pulsed dye laser therapy demonstrating lightening at lasered sites

performed with laser while protecting the surrounding dermis. The PDL is the standard treatment for PWS and the preferred treatment by many patients [22]. Small circular spots of cleared malformation can be observed following IPL (Fig. 3). Repeat treatments address the intervening areas while controlling growth of the entire lesion.

Intense pulsed light (IPL) therapy is also commonly used to ablate the vascular stain created by capillary malformations. The benefit of IPL is a broad based rectangular treatment spot. However, participants reviewed by Faurschou et al. preferred PDL to IPL based on clinical efficacy [22]. PDL treatments are usually performed every 4-6 weeks, though some research advocates greater improvement with shorter intervals between treatment sessions [26]. For young patients when anesthesia is required, spacing the treatment interval to $2-3$ months may be elected. Treatment sessions should be discontinued when there is no further improvement in appearance of the malformation (plateau).

Pulsed dye laser treatments for PWS may commence as early as infancy. Safety and efficacy of early treatment has been demonstrated. Some report a better response to PDL in the pediatric population compared to adults [27]. In a study by Ashinoff et al., $83 \%$ of the infants treated experienced over $50 \%$ lightening of their PWS after an average 2.9 sessions. In addition, $45 \%$ of patients demonstrated $75 \%$ lightening after an average 3.8 sessions. There were no reported skin complications in this study [28].

Less than $10 \%$ of PWS experience complete clearance with PDL treatments. PWS may be resistant to PDL, with approximately $20 \%$ of lesions failing to respond at all [29]. Postulated reasons for PWS resistance include patient age, lesion size, anatomical location, skin thickness, vessel characteristics, and number of prior treatments [30]. Trigeminal distribution and midfacial lesions are thought to be poor responders. $16-50 \%$ of patients report darkening of their PWS approximately 5 years after completing PDL treatments [31,32]. This is thought to be due to regeneration and revascularization of the treated blood vessels [33].

Other laser and light therapies have been tested for PDLresistant PWS. Specifically, Alexandrite lasers have shown some beneficial effects. This is thought to be due to the Alexandrite laser's increased depth of penetration, longer wavelength, and increased affinity to deoxyhemoglobin, which is more abundant in large capillary, venular and venous channels [34]. The Gentle YAG laser has also shown some promising results for PDL-resistant PWS [30]. IPL may also be effective [35].

New instruments and adjuncts to treatment for PWS are currently being tested. Quantitative measurement of PWS clearance after laser treatments has been performed. Frigerio et al. were able to accurately measure the change in area and volume of PWS after treatments by using $3 \mathrm{dMD}$ photogrammetric software. However, their results did not correlate well with clinical effects [20]. Other new adjuncts to laser treatment include site-specific pharmacolaser therapy and perioperative changes in the lesions hemodynamics $[30,35]$.

Topical application of rapamycin, an antiangiogenic agent, when combined with PDL sessions, has shown some potentially promising results in the treatment of PWS. Studies in animal models have indicated reduced regeneration and revascularization of the photocoagulated vessels by suppressing angiogenesis pathways. These results suggest that topical rapamycin with PDL treatments might improve efficacy and extend the intervals between successive PWS treatments [33, 35-38].

Indocyanine green-augmented diode laser (ICG + DL) therapy has also been studied in PWS laser therapy. When compared to standard PDL, ICG + DL demonstrated improved cosmetic outcomes. This was based on ratings conducted by patients in a study performed by Klein et al. in 2012. The investigators themselves, however, did not find any statistically significant difference in clearance rates or cosmetic appearance. Patients also rated the pain associated with ICG + DL treatment to be worse than PDL alone [39]. Another study by Klein et al. in 2013 concluded that only a small portion of patients with capillary malformations benefit from ICG + DL therapy [40].

\section{Venous Malformations}

Venous malformations (VMs) are the third most common vascular malformation after hemangiomas and lymphatic malformations. They frequently occur in the head and neck 
Fig. $4 \mathrm{Nd}$ :YAG laser fiber attached to a Hopkins telescope for treatment of laryngeal and distal aerodigestive tract lesions. a Equipment setup. b Close-up view of laser fiber attachment to telescope
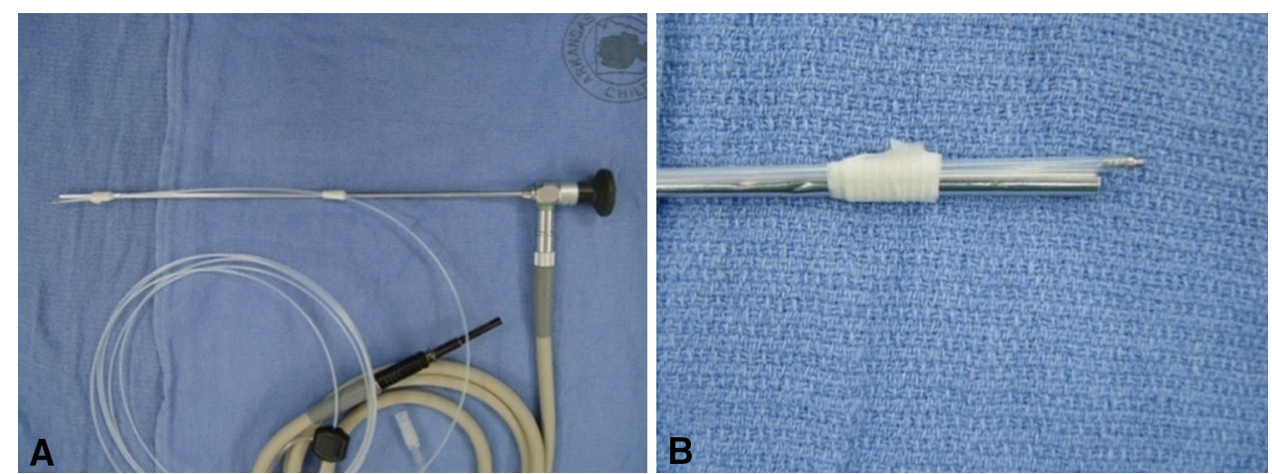

to include the lip, tongue, neck, muscles of mastication, and upper aerodigestive tract. VMs may be isolated or multifocal with a variation in size and location. They frequently occur in muscles and mucous membranes [41-44]. They are composed of thin-walled and tortuous veins [45]. They are present at birth but become more apparent later in life from gradual vascular expansion. Rapid growth may occur during hormonal fluctuations (such as puberty or oral contraceptive use), prior treatment, or trauma. VMs also undergo expansion with periods of acute thrombosis. This is secondary to local intravascular coagulation (LIC) and is thought to be the source of acute or chronic pain in patients with VMs. LIC is unique to VMs compared to other vascular anomalies. On examination, VMs are soft and compressible, with both deep and superficial components leading to a blue hue on the surface. As expected for venous channels, VMs expand when the affected site is below the level of the heart, during exercise or recumbence, or during a Valsalva maneuver [44].

Due to their relentless expansion, VMs will require treatment, but the timing and type of treatment is variable. With head and neck VMs, single or multimodal treatment may be instituted depending on the lesion size and location. Laser therapy, sclerotherapy, surgical excision, or a combination of these treatment modalities may be necessary for disease control. Those lesions that may be treated with laser treatment are superficial skin VMs, superficial and deep mucosal VMs, and some deep VMs in tongue, parotid, or muscle [44].

Richter and Braswell previously outlined the therapeutic options for treatment of head and neck VMs, including laser therapy [44]. For laser treatment, the Nd:YAG and Alexandrite lasers are employed due to their longer wavelengths and affinity for deoxyhemoglobin located within venous channels [35].

The Nd:YAG laser is effective at treating mucosal VMs. For distal aerodigestive lesions the Nd:YAG laser fiber is attached to a Hopkins telescope so direct visualization and treatment of the lesion can be simultaneous performed (Fig. 4). Immediate reduction is size of mucosal VMs can be observed. VMs of the distal trachea, larynx, hypopharynx, and tongue base can be treated in this fashion at any age. The result of a single treatment is often sustained for several months. Thus, treatment sessions are frequently spaced 3 months apart until the VMs are well controlled. An average of four treatments may be necessary, though some report fewer are required when a low burden of mucosal disease exists. One to two treatments may be sufficient in these patients [43]. VMs of the lips, buccal mucosa, tongue, and gingiva can be managed in the same fashion using a small handheld Nd:YAG laser. A short course of oral steroids help reduced postoperative mucosa edema and discomfort. Complications are rare but include mucosal sloughing, scarring and bleeding [41, 43, 44, 46].

Venous malformations that involve the skin may be treated with the Gentle YAG laser or Alexandrite laser. Large superficial venous channels are better treated by the Gentle YAG laser. Thin venous telangiectasias with diffuse skin involvement respond well to Alexandrite laser [44]. Good results have been reported for treatment of head and neck VMs (both skin and mucosal lesions) with the Nd:YAG laser. In large or complex cervicofacial VMs, laser therapy may only provides one mode of managing the lesions as sclerotherapy and surgery are also employed. The objective in these cases is to ablate the mucocutaneous portions of the disease so that they are thickened and protected when subsequent interventions are required [46]. Cryogen is emitted prior to the laser during Gentle YAG laser therapy to protect the skin from thermal damage $[44,46]$.

Surgical excision and sclerotherapy of deep VMs can cause significant, albeit temporary, risk to motor and sensory nerves. Therefore, interstitial (intralesional) laser treatment provides an alternative to treating deep large vessel VMs. VMs of the tongue, deep parotid gland, masseter muscle, and neck may be treated with this therapy. The Nd:YAG glass laser fiber is inserted into a 14-gauge needle in the VM, often under ultrasound guidance (Fig. 5). Continuous or pulse duration can be used as the laser fiber and needle are slowly withdrawn from the VM. This allows for targeted laser ablation from within the deep vessels [41, 47]. Immediate shrinking of the malformation is often visible, and an audible pop of the vessel occurs during treatment [44]. 
Fig. 5 Interstitial Nd:YAG treatment of venous malformation (VM) of the left buccal space. a Pre-treatment axial T2-weighted MRI of the neck showing hyperintense lesion of the left buccal space indicating location of VM. b The Nd:YAG laser fiber being inserted into a 14-gauge needle. c Transoral insertion of the needle and laser fiber into the lesion. d Ultrasound guidance of needle placement into lesion for interstitial laser ablation
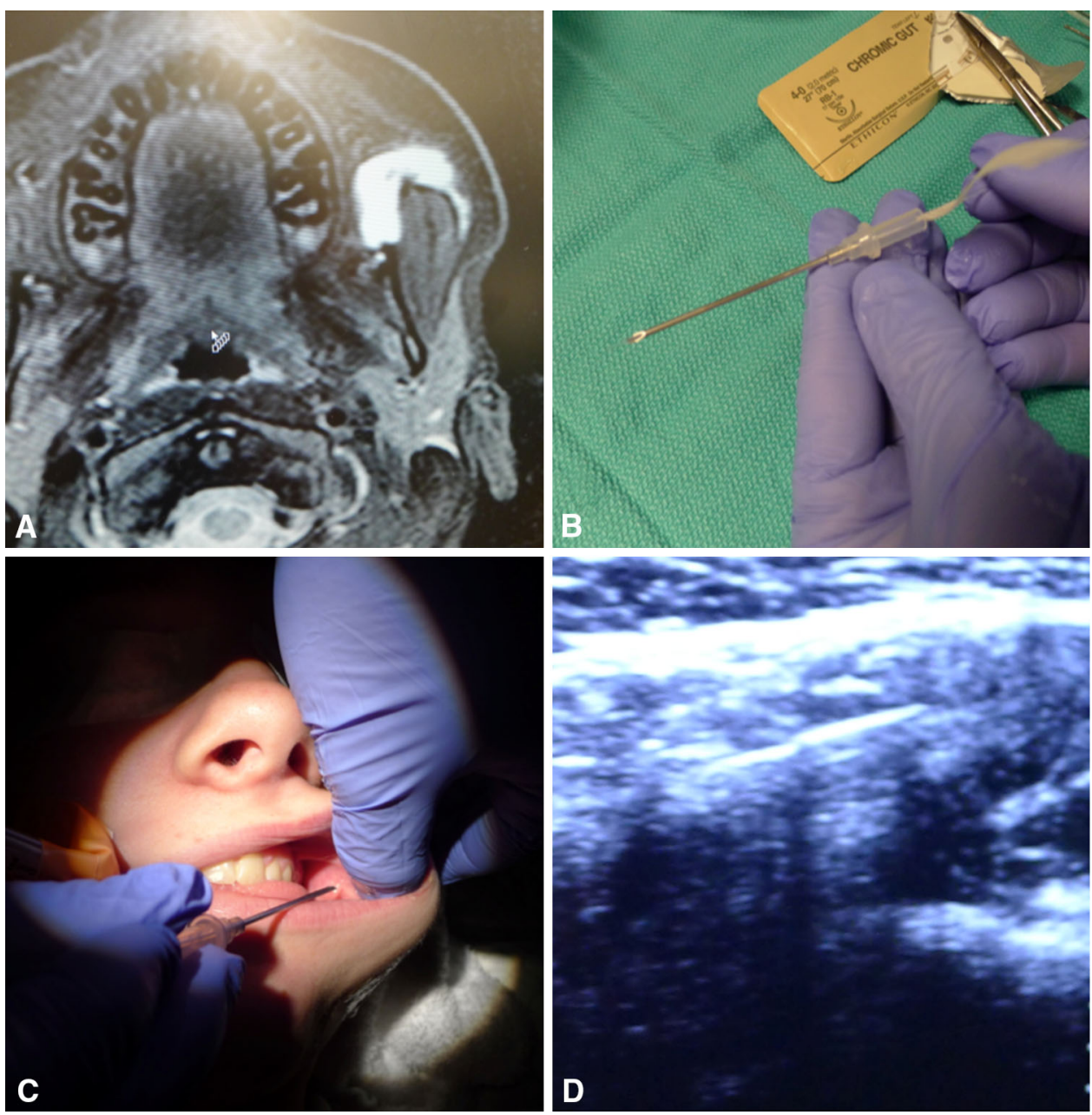

\section{Conclusion}

Laser therapy for treatment of vascular anomalies has improved significantly over the last three decades to treat hemangiomas, capillary malformations and VMs of the head and neck. The pulse dye and Nd:YAG lasers can be employed for the majority of skin and mucosal lesions. Deep vascular anomalies can also be treated using interstitial laser therapy. Complications and risks are uncommon. Patient outcomes and satisfaction advocate the use of lasers for vascular anomalies. Laser is often employed in conjunction with other therapeutic modalities in large and complex lesions.

\section{Compliance with Ethics Guidelines}

Conflict of Interest Tara Rosenberg declares that she has no conflict of interest. Gresham Richter declares that he has no conflict of interest.

Human and Animal Rights and Informed Consent No human or animal studies performed by the authors: This article does not contain any studies with human or animal subjects performed by any of the authors.

\section{References}

Papers of particular interest, published recently, have been highlighted as:

- Of major importance

1. Mulliken JB, Glowacki J. Hemangiomas and vascular malformations in infants and children: a classification based on endothelial characteristics. Plast Reconstr Surg. 1982;69(3):412-22.

2. Mulliken JB, Glowacki J. Classification of pediatric vascular lesions. Plast Reconstr Surg. 1982;70(1):120-1.

3. Enjolras O, Wassef M, Chapot R. Color atlas of vascular tumors and vascular malformations, vol. x. New York: Cambridge University Press; 2007. p. 299.

4. Keller GS, Toft KM. Lasers in aesthetic surgery, vol. xvi. New York: Thieme; 2001. p. 368.

5. Anderson RR, Parrish JA. Microvasculature can be selectively damaged using dye lasers: a basic theory and experimental evidence in human skin. Lasers Surg Med. 1981;1(3):263-76.

6. Anderson RR, Parrish JA. Selective photothermolysis: precise microsurgery by selective absorption of pulsed radiation. Science. 1983;220(4596):524-7.

7. - Craig LM and Alster TS. Vascular skin lesions in children: a review of laser surgical and medical treatments. Dermatol Surg. 2013; 39(8):1137-46. This is a brief overview of treatment 
options for some vascular anomalies in children. Pertinent background information is discussed.

8. - Bencini PL et al. Laser use for cutaneous vascular alterations of cosmetic interest. Dermatol Ther. 2012; 25(4):340-51. This article gives information on laser basics and application to treatment of vascular anomalies/lesions.

9. - Franca $\mathrm{K}$ et al. Lasers for cutaneous congenital vascular lesions: a comprehensive overview and update. Lasers Med Sci. 2013; 28(4):1197-204. This is a brief review of common lasers used in treatment of vascular anomalies.

10. Brightman LA, et al. Ablative fractional resurfacing for involuted hemangioma residuum. Arch Dermatol. 2012;148(11):1294-8.

11. Batta K, et al. Randomised controlled study of early pulsed dye laser treatment of uncomplicated childhood haemangiomas: results of a 1 year analysis. Lancet. 2002;360(9332):521-7.

12. Kono $\mathrm{T}$, et al. Comparison study of a traditional pulsed dye laser versus a long-pulsed dye laser in the treatment of early childhood hemangiomas. Lasers Surg Med. 2006;38(2):112-5.

13. Witman PM, et al. Complications following pulsed dye laser treatment of superficial hemangiomas. Lasers Surg Med. 2006;38(2):116-23.

14. Garden JM, Bakus AD, Paller AS. Treatment of cutaneous hemangiomas by the flashlamp-pumped pulsed dye laser: prospective analysis. J Pediatr. 1992;120(4 Pt 1):555-60.

15. Poetke M, Philipp C, Berlien HP. Flashlamp-pumped pulsed dye laser for hemangiomas in infancy: treatment of superficial vs mixed hemangiomas. Arch Dermatol. 2000;136(5):628-32.

16. Bitar MA, Moukarbel RV, Zalzal GH. Management of congenital subglottic hemangioma: trends and success over the past 17 years. Otolaryngol Head Neck Surg. 2005;132(2):226-31.

17. Raol N, et al. Propranolol for the treatment of subglottic hemangiomas. Int J Pediatr Otorhinolaryngol. 2011;75(12):1510-4.

18. Marqueling AL, et al. Propranolol and infantile hemangiomas four years later: a systematic review. Pediatr Dermatol. 2013;30(2):182-91.

19. Menezes MD, et al. Status of propranolol for treatment of infantile hemangioma and description of a randomized clinical trial. Ann Otol Rhinol Laryngol. 2011;120(10):686-95.

20. Frigerio A, Bhama PK, Tan OT. Quantitative three-dimensional assessment of port-wine stain clearance after laser treatments. Lasers Surg Med. 2013;45(10):633-8.

21. Habif TP. Clinical dermatology: a color guide to diagnosis and therapy, vol. xv. 4th ed. Edinburgh: Mosby; 2004. p. 1004.

22. Faurschou A, et al. Lasers or light sources for treating port-wine stains. Cochrane Database Syst Rev. 2011;11:CD007152.

23. Malm M, Carlberg M. Port-wine stain: a surgical and psychological problem. Ann Plast Surg. 1988;20(6):512-6.

24. Shirley MD, et al. Sturge-Weber syndrome and port-wine stains caused by somatic mutation in GNAQ. $N$ Engl J Med. 2013;368(21):1971-9.

25. Ch'ng S, Tan ST. Facial port-wine stains-clinical stratification and risks of neuro-ocular involvement. J Plast Reconstr Aesthet Surg. 2008;61(8):889-93.

26. Tomson $\mathrm{N}$, et al. The treatment of port-wine stains with the pulsed-dye laser at 2 week and 6 week intervals: a comparative study. Br J Dermatol. 2006;154(4):676-9.

27. Stier MF, Glick SA, Hirsch RJ. Laser treatment of pediatric vascular lesions: port wine stains and hemangiomas. J Am Acad Dermatol. 2008;58(2):261-85.

28. Ashinoff R, Geronemus RG. Flashlamp-pumped pulsed dye laser for port-wine stains in infancy: earlier versus later treatment. J Am Acad Dermatol. 1991;24(3):467-72.
29. Lanigan SW. Port-wine stains unresponsive to pulsed dye laser: explanations and solutions. Br J Dermatol. 1998;139(2):173-7.

30. Savas JA, et al. Pulsed dye laser-resistant port-wine stains: mechanisms of resistance and implications for treatment. Br J Dermatol. 2013;168(5):941-53.

31. Michel S, Landthaler M, Hohenleutner U. Recurrence of portwine stains after treatment with the flashlamp-pumped pulsed dye laser. Br J Dermatol. 2000;143(6):1230-4.

32. Orten SS, et al. Port-wine stains. An assessment of 5 years of treatment. Arch Otolaryngol Head Neck Surg. 1996;122(11): 1174-9.

33. Tan W, et al. Topical rapamycin suppresses the angiogenesis pathways induced by pulsed dye laser: molecular mechanisms of inhibition of regeneration and revascularization of photocoagulated cutaneous blood vessels. Lasers Surg Med. 2012;44(10): 796-804.

34. Izikson L, Anderson RR. Treatment endpoints for resistant port wine stains with a $755 \mathrm{~nm}$ laser. J Cosmet Laser Ther. 2009;11(1):52-5.

35. Chen JK, et al. An overview of clinical and experimental treatment modalities for port wine stains. J Am Acad Dermatol. 2012;67(2):289-304.

36. Jia W, et al. Long-term blood vessel removal with combined laser and topical rapamycin antiangiogenic therapy: implications for effective port wine stain treatment. Lasers Surg Med. 2010;42(2):105-12.

37. Loewe $\mathrm{R}$, et al. Stem cell marker upregulation in normal cutaneous vessels following pulsed-dye laser exposure and its abrogation by concurrent rapamycin administration: implications for treatment of port-wine stain birthmarks. J Cutan Pathol. 2010;37(Suppl 1):76-82.

38. Phung TL, et al. Can the wound healing response of human skin be modulated after laser treatment and the effects of exposure extended? Implications on the combined use of the pulsed dye laser and a topical angiogenesis inhibitor for treatment of port wine stain birthmarks. Lasers Surg Med. 2008;40(1):1-5.

39. Klein A, et al. Indocyanine green-augmented diode laser treatment of port-wine stains: clinical and histological evidence for a new treatment option from a randomized controlled trial. Br J Dermatol. 2012;167(2):333-42.

40. Klein A, et al. A randomized controlled trial to optimize indocyanine green-augmented diode laser therapy of capillary malformations. Lasers Surg Med. 2013;45(4):216-24.

41. Glade RS, et al. Diagnosis and management of pediatric cervicofacial venous malformations: retrospective review from a vascular anomalies center. Laryngoscope. 2010;120(2):229-35.

42. Konez O, Burrows PE, Mulliken JB. Cervicofacial venous malformations. MRI features and interventional strategies. Interv Neuroradiol. 2002;8(3):227-34.

43. Eivazi B, et al. Laser treatment of mucosal venous malformations of the upper aerodigestive tract in 50 patients. Lasers Med Sci. 2010;25(4):571-6.

44. Richter GT, Braswell L. Management of venous malformations. Facial Plast Surg. 2012;28(6):603-10.

45. North PE, Mihm MC Jr. Histopathological diagnosis of infantile hemangiomas and vascular malformations. Facial Plast Surg Clin North Am. 2001;9(4):505-24.

46. Scherer K, Waner M. Nd:YAG lasers $(1,064 \mathrm{~nm})$ in the treatment of venous malformations of the face and neck: challenges and benefits. Lasers Med Sci. 2007;22(2):119-26.

47. Chang CJ, Fisher DM, Chen YR. Intralesional photocoagulation of vascular anomalies of the tongue. $\mathrm{Br} \mathrm{J}$ Plast Surg. 1999;52(3):178-81. 